\title{
Indoor Air Quality Study on Fiber Glass Industry
}

\author{
Amir Alhaddad, Baderiya Al-Abdulmohsin \\ Chemical Engineering Department, Kuwait University, Kuwait City, Kuwait \\ Email: amir.alhaddad@ku.edu.kw, bsalah@alghanim.com
}

Received October 2012

\begin{abstract}
The most hazardous chemical used in fiber glass industry are: formaldehyde, phenol and ammonia. The chemicals were monitored in an industry in Kuwait to investigate the indoor air quality of the facility. It was found that all these chemicals were within the OSHA standards but formaldehyde exceeded KEPA standards $(0.1 \mathrm{ppm})$ in the curing area. It was found that lower density of fiber glass product leads to higher concentration of pollutants in the atmosphere and vise versa. Moreover, higher thickness causes higher concentration of pollutants in the atmosphere.
\end{abstract}

Keywords: Indoor Air Quality; Fiber Glass Industry; Hazardous Pollutants

\section{Introduction}

Indoor air quality (IAQ) is defined as the nature of air that affects the health and well-being of occupants. It differs from industrial indicators of acceptability, such as threshold limit values, as the latter primarily reflect concern for control of potential hazards. A more technical definition of IAQ is related to how well indoor air satisfies the three basic requirements for human occupancy which are thermal acceptability, maintenance of normal concentrations of respiratory gases; and dilution and removal of contaminants to levels below health or odour discomfort thresholds. The following is a brief review of recent studies related to indoor air quality conducted in Kuwait and around the world. Yassin et al. [4] measured concentrations of $\mathrm{PM}_{2.5}$ at indoor settings in several houses with various residential mediums in Kuwait. Data were collected by using a Dust-Trak personal sampler over 24 hours. The places included kitchen, living room, and bedrooms in all studied houses. It was found that the concentrations of $\mathrm{PM}_{2.5}$ were higher than the EPA daily NAAQS in the kitchen and living rooms where the lower concentrations were recorded in the bedrooms. These results reflect bad effect on human health in Kuwait in compared with houses in the United States, the United Kingdom and Greece. Al-Rashidi et al. [2] investigated the impact of ventilation modes on carbon dioxide concentrations in Kuwait classrooms. The levels of $\mathrm{CO}_{2}$ were measured during natural and air conditioned ventilation modes. The study conducted inside 10 elementarylevel classrooms for children in the 6 - 10 years age in three schools. The obtained data showed that the concentrations of $\mathrm{CO}_{2}$ with air conditioned operation were higher than concentrations during natural ventilation. The concentrations of $\mathrm{CO}_{2}$ exceeded the recommended standards that some strategies and arrangements should be taken to reduce the $\mathrm{CO}_{2}$ levels to allowable limits. Bohlandt et al. [1] measured concentrations of the trace metals cerium (Ce), anthanum (La) and cadmium (Cd) in indoor air with high Environmental tobacco smoke load. The samples were collected in 3 smokers and 7 nonsmokers' households in addition to 28 hospitals in Southern Germany. Data was conducted continuously for seven days in every season in the houses and for 4 hours during the main visiting hours in the hospitals. Analysis of all measured values showed that high concentrations of Ce and La were found in smokers' households and hospitals which were above the international indoor air quality standards. Fiedoruk [3] examined indoor air quality inside the cabin of an airplane occupied 150 passengers on board. The concentration of $\mathrm{CO}_{2}$, air temperature, pressure and humidity were measured during the flight that lasted three hours. Results showed that the concentration of $\mathrm{CO}_{2}$ was higher than international standards. Penpatra et al. [5] studied the effects of exposure to glass microfibers on respiratory and skin symptoms, asthma and lung functions. The study included 102 workers from four microfiber factories in Thailand. The workers answered questionnaire on respiratory health, occupational exposures and life style factors and performed spirometry. The dust concentrations were monitored in the air of factories during 2004 and 2005 by the gravimetric analysis method (NIOSH method 0600). Results showed that exposure to glass microfibers increase the risk of the respiratory and skin symptoms. On the other hand, exposure to sensitizing chemicals increased the risk of cough and nasal symptoms. Sait et al. [6] assessed health risks of 
volatile organic compounds in three primary schools in Izmir, Turkey. Primary schools accommodate children aged 7 - 14 for about 5 - 8 hours daily. Concentrations of VOCs were measured in spring, winter, and fall terms. A thermal desorption-GC-MS system was used to analyze VOCs where Formaldehyde analysis was performed using an HPLC instrument. A health risk assessment was performed to detect odours, sensory irritation, chronic toxic effects and cancer. Results showed that Formaldehyde appears to be the pollutant of greatest concern with high chronic toxic and carcinogenic risk based on the health assessment followed by naphthalene, benzene, toluene because of their chronic effects.

Due to the nature of the fiber glass industry; involving the use of hazardous materials, it is essential to undergo an indoor air quality study to monitor the surrounding pollutants. In the present study the primary objective of IAQ is to ensure that the potential environmental impacts of the industry are identified, and considered during the running process. This is done by first studying the over overall process and identifying the major areas of concern. These areas are monitored and the environmental impacts studied and analyzed to formulate a suitable and effective solution for any problems if identified. As well as provide well-documented information to Kuwait's EPA for evaluation and approval for environmental compliance. Finally, this study concentrated on chemical pollutants rather than particulate matters because PM studied extensively in a previous study.

\section{Data Collection}

Data were collected in this study by using UV Sentry equipment. It consists of an ultra violet light generated from a source, usually deuterium or xenon lamp. The light is emitted through the area to a receiver where it is collected and concentrated using standard telescope optics. Once inside the spectrometer, the light is broken out into its various wavelengths by sending it through a holographic grating. The light then hits the CCD array which in turn charges the capacitor. The capacitors are discharged at a sample rate set by the user and the light signal at each light frequency is proportional to the total charge of each capacitor. The concentrated light is then passed through an input lens into the spectrometer via a fiber optic coupling.

The data were measured over a period of three months and divided into two periods, the first period was from 1/Jan/2012 to 16/Feb/2012 and the second period was from 17/Feb/2012 to end of March. The pollutants that have been monitored were Ammonia, Formaldehyde, and Phenol. The device was placed in 5 different areas throughout the process line and in each area data were collected for 5 days, this was done twice (two rounds), which accumulated to a total of three months. The variables that remained constant during the experiment were the height and the duration of time which was 5 days. The height was maintained at $1.75 \mathrm{~m}$ from platform/ground level which is equivalent of the height of the average adult male. The distance between the sender and the emitter are shown within the Table 1.

Once the raw data has been collected, all records were compiled into one file with special coding for each location to distinguish between records. The raw data was then transferred to SPSS software for statistical analysis and processed through 3 steps.

\section{Statistical Analysis}

This part is about introducing and summarizing the collected data using some statistical tools such as mean, median, variance, skewness, upper quartile, lower quartile. Tables $\mathbf{2}$ and $\mathbf{3}$ describe the overall statistics for the collected data in general. A total of 8024 data points were collected for each pollutant. Data points that did not "pass" a statistical were eliminated from the study.

As it is clear from the Figure 1, the more density sizes the less concentration of Ammonia values. Also, the figure shows that the variation of the data is decreasing when the density size is increasing as indicated by the length of the whisker of the box-plot. So, the figure assures that the more density size the less concentration of Ammonia.

As it is clear from Figure 2, the more thickness sizes the more concentration of Ammonia values. Also, the figure shows that the variation of the data is decreasing when the thickness is increasing as indicated by the length of the whisker of the box-plot. So, the figure assures that the more thick sizes the more concentration of Ammonia.

\section{Comparison against KEPA and OSHA Standards}

To assess the indoor air quality the concentrations of ammonia, a formaldehyde and phenol pollutants were compared against local and international standards (KEPA and OSHA). The comparison was made for the measured

Table 1. List of locations measured with distance between sender and emitter of UV Sentry.

\begin{tabular}{ccc}
\hline Area & Location & Distance \\
\hline 1 & Forming area & 30 meters \\
2 & Curing oven inlet & 14 meters \\
3 & Curing oven outlet & 14 meters \\
4 & Chopper area & 15 meters \\
5 & Packing & 35 meters \\
\hline
\end{tabular}


Table 2. Overall descriptive statistics for study variables.

\begin{tabular}{cccc}
\hline \multirow{2}{*}{ Pollutants } & $\mathrm{N}$ & Minimum & Maximum \\
\cline { 2 - 4 } & Statistic & Statistic & Statistic \\
\hline Ammonia & 9367 & 0.00 & 3.38 \\
Formaldehyde & 10153 & 0.00 & 3.27 \\
Phenol & 10301 & 0.016 & 0.197 \\
\hline
\end{tabular}

Table 3. Overall descriptive statistics for study variables.

\begin{tabular}{lccccc}
\hline \multirow{2}{*}{ Pollutants } & \multicolumn{2}{c}{ Mean } & Variance & \multicolumn{2}{c}{ Skewness } \\
\cline { 2 - 6 } & Statistic & Std. Error & Statistic & Statistic & Std. Error \\
\hline Ammonia & 0.7988 & 0.0085 & 0.681 & 1.402 & 0.025 \\
Formaldehyde & 1.0420 & 0.0074 & 0.552 & 0.440 & 0.024 \\
Phenol & 0.0457 & 0.00024 & 0.001 & 1.480 & 0.024 \\
\hline
\end{tabular}

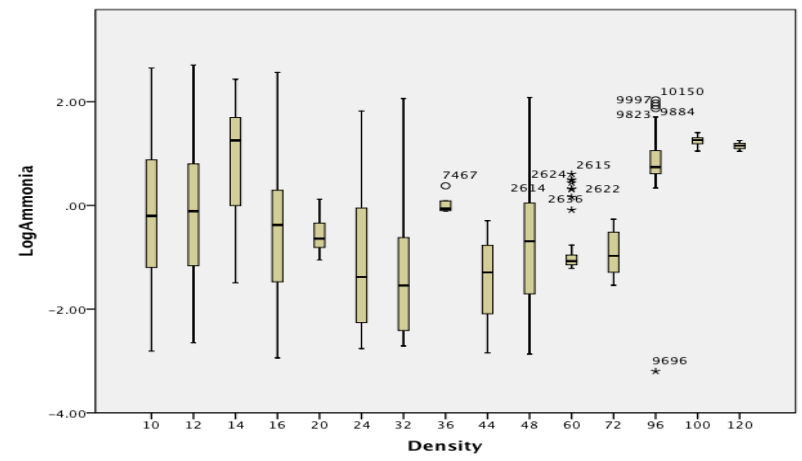

Figure 1. Box-plot change for Ln of Ammonia based on density size.

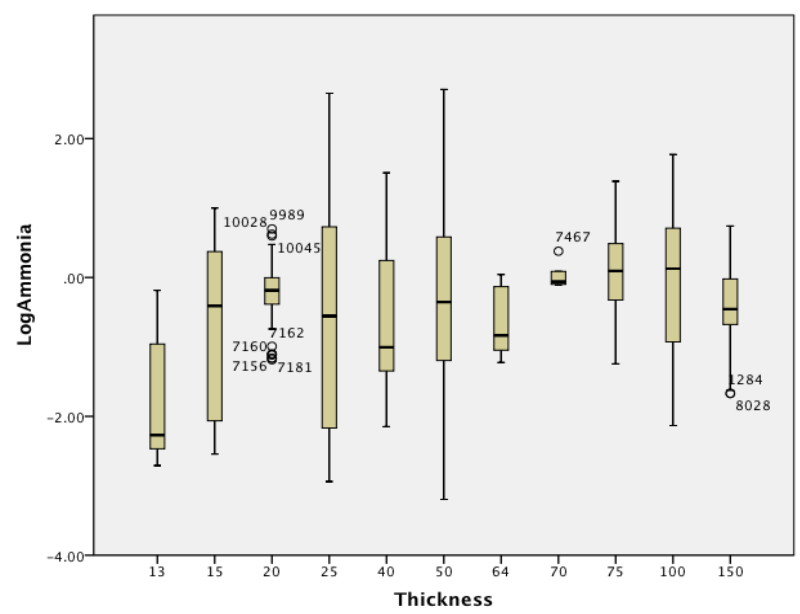

Figure 2. Box-plot change for Ln of Ammonia based on thickness size.

data from January 2012 till April 2012.

Kuwait regulations KEPA and OSHA standards limit ammonia in the indoor environment to be 35 ppm and 15 ppm respectively for 15 minute exposure. From Figure 3 obtained in this study it is evident that all areas showed that ammonia levels are within both KEPA and OSHA
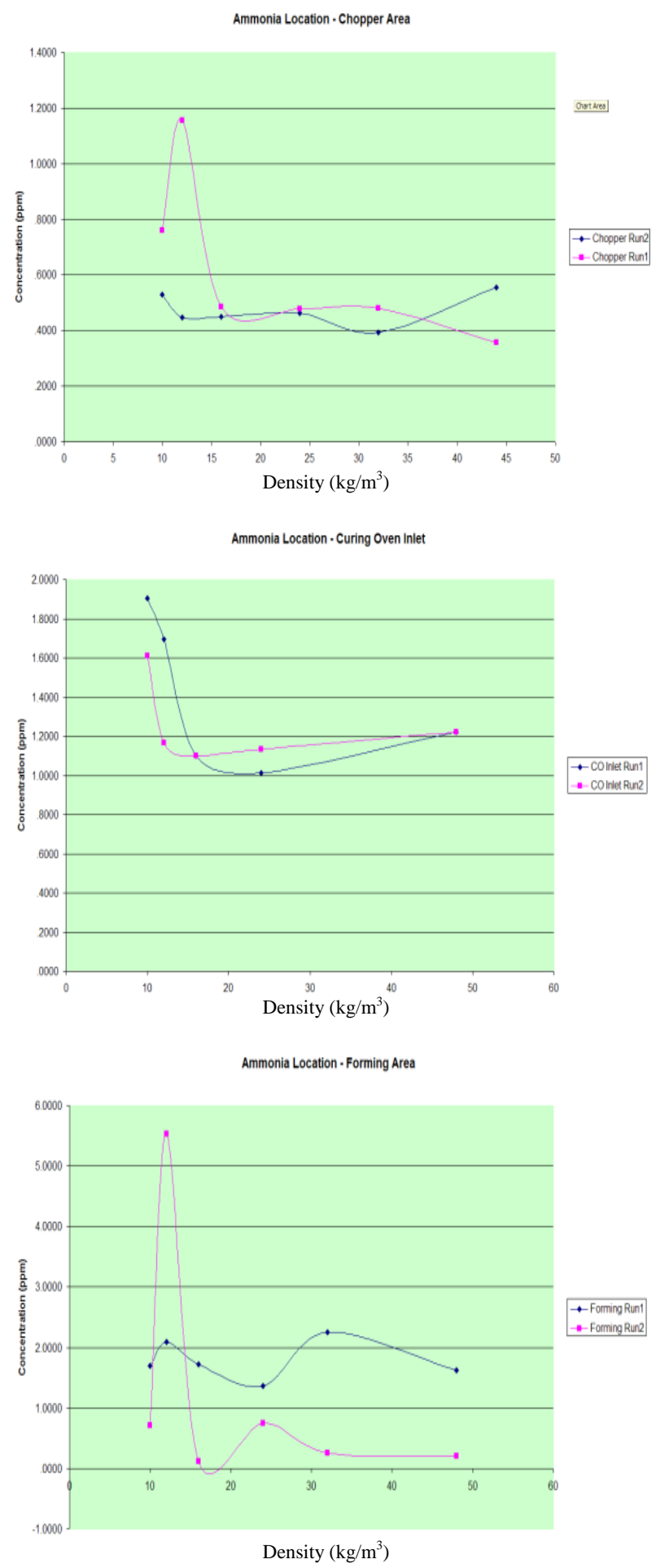

Figure 3. Concentrations of Ammonia in the study locations.

regulations. In curing oven outlet and forming area locations ammonia averages at approximately 2 ppm for all densities. Moreover, these areas are exposed and are liable to fumes while the lowest average readings for ammonia was observed in packing area. This was expected 
since the packing is found at the end of the process line and the product has cooled down leading to lower binder volatility within the product.

Formaldehyde is considered one of the main pollutants in this industry due to its severe health hazards. However standards differ between KEPA and OSHA with 0.1 ppm and 2 ppm respectively. This huge difference between regulations may create conflict in the discussion of the results. The highest concentration of formaldehyde was found in chopper area with a maximum of $2.55 \mathrm{ppm}$ and averaging at $2 \mathrm{ppm}$. The concentrations of in curing oven outlet and forming area were $1.82 \mathrm{ppm}$ and $1.9 \mathrm{ppm}$ respectively as shown in Figure 4. The concentrations although barely below OSHA regulations, they are much higher than KEPA regulations. The Lowest concentrations were found in packing area, as in the case of other component analysis. Although concentrations at curing oven and forming area were within OSHA standards, these areas are prone to high concentrations due to the possibility of further reactions taking place because of the nature of these process areas.

Both KEPA and OSHA standards require phenol levels to be under 5 ppm for an $8 \mathrm{hr}$ average. In all areas as shown in Figure 5, phenol levels were observed to be significantly less than $5 \mathrm{ppm}$. A maximum concentration of $0.139 \mathrm{ppm}$ of Phenol was recorded in forming area
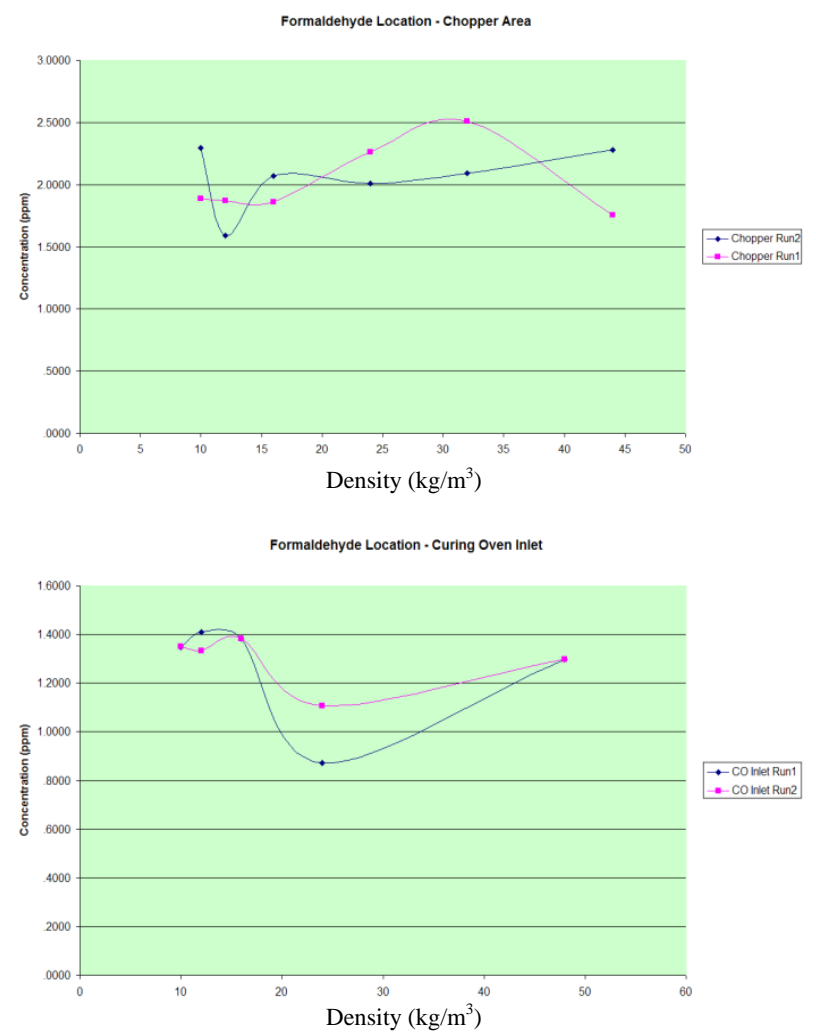

Figure 4. Concentrations of formaldahyde in the study locations.

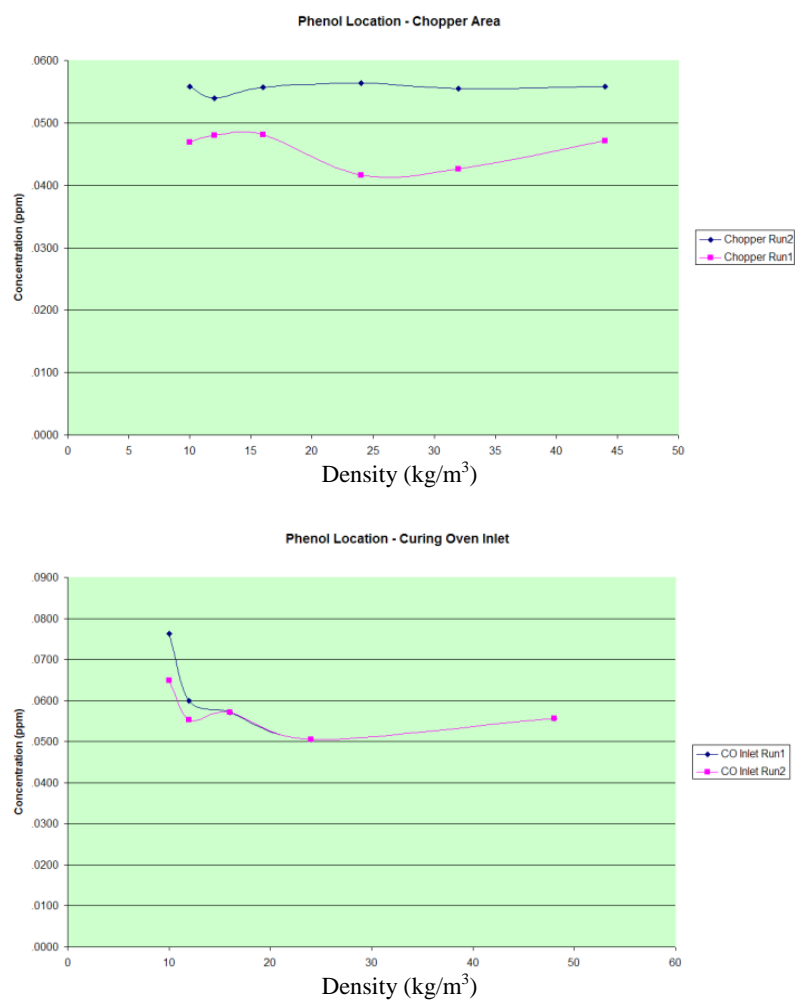

Figure 5. Concentrations of phenol in the study locations.

and a low of $0.028 \mathrm{ppm}$. The lowest concentration of phenol was found in packing area, with an average of 0.022 ppm for all densities.

\section{Conclusion}

Indoor air quality of fiber glass industry investigates met OSHA standards for the pollutants studied; formaldehyde, phenol and ammonia. Formaldehyde exceeded KEPA standards in the curing area. These standards are under revision in Kuwait and the new standards will be out in mid 2013. The curing (reactor) area in the fiber glass industry is the point of highest pollutants concentration and can be used as reference to monitor IAQ of the facility. The source of hazardous pollutants in the fiber glass industry is the "binder" used to produce the final product. The higher the density, the lower pollutants concentration in the air (pollutants are captured in the product). The higher the thickness (lower concentration), the higher the pollutants in the air.

\section{Acknowledgements}

This research was supported by the Kuwait University.

\section{REFERENCES}

[1] A. Prüss-Ustün, C. Vickers, P. Haefliger and R. Bertollini, "Knowns and Unknowns on Burden of Disease Due to 
Chemicals: A Systematic Review,” Environmental Health, Vol. 10, 2011, p. 9.

http://dx.doi.org/10.1016/j.scitotenv.2011.11.017

[2] A. Bohlandt, R. Schierl, J. Diemer, C. Koch, G. Bolte, M. Kiranoglu, H. Fromme and D. Nowak, "High Concentrations of Cadmium, Cerium and Lanthanum in Indoor Air Due to Environmental Tobacco Smoke," Science of the Total Environment, Vol. 414, 2012, pp. 738-741. http://dx.doi.org/10.1016/j.scitotenv.2011.11.017

[3] E. Gallego, X. Roca, J. F. Perales and X. Guardino, “Determining Indoor Air Quality and Identifying the Origin of Odour Episodes in Indoor Environments,” Journal of Environmental Sciences, Vol. 21, 2009, pp. 33-339. http://dx.doi.org/10.1016/S1001-0742(08)62273-1

[4] K. G1adyszewska-Fiedoruk, "Indoor Air Quality in the Cabin of an Airliner,” Journal of Air Transport Management, Vol. 20, 2012, pp. 28-30.

[5] K. Al-Rashidia, D. Lovedaya and N. Al-Mutawab, "Impact of Ventilation Modes on Carbon Dioxide Concentra- tion Levels in Kuwait Classrooms,” Energy and Buildings, Vol. 47, 2012, pp. 540-549.

http://dx.doi.org/10.1016/j.enbuild.2011.12.030

[6] M. Yassin, B. AlThaqeb and E. Al-Mutiri, "Assessment of Indoor $\mathrm{PM}_{2.5}$ in Different Residential Environments," Atmospheric Environment, Vol. 56, 2012, pp. 65-68. http://dx.doi.org/10.1016/j.atmosenv.2012.03.051

[7] P. Sripaiboonkij, N. Sripaiboonkij, W. Phanprasit and M. S. Jaakkola, "Respiratory and Skin Health among Glass Microfiber Production Workers: A Cross-Sectional Study,” Environmental Health, Vol. 8, 2009, p. 36. http://dx.doi.org/10.1186/1476-069X-8-36

[8] S. C. Sofuoglua, G. Aslanb, F. Inal and A. Sofuoglua, "An Assessment of Indoor Air Concentrations and Health Risks of Volatile Organic Compounds in Three Primary Schools," International Journal of Hygiene and Environmental Health, Vol. 214, 2001, pp. 36-46. http://dx.doi.org/10.1016/j.ijheh.2010.08.008 